\title{
Tingkat Kematangan Infrastruktur Teknologi Informasi Pada Domain Acquire and Implement Menggunakan COBIT 4.1 (Studi Kasus: UPT Perpustakaan Universitas Pembangunan Nasional "Veteran" Jawa Timur)
}

\author{
Ronggo Alit ${ }^{*}$, Icha Dian Pratiwi ${ }^{2}$, Mohammad Idhom ${ }^{3}$ \\ 1,2,3 Universitas Pembangunan Nasional "Veteran" Surabaya \\ ronggoa@gmail.com*
}

\begin{abstract}
Abstrak
Berdasarkan hasil wawancara UPT Perpustakaan kekurangan perangkat komputer dan masih menggunakan server milik UPT Telematika serta kecepatan akses WiFi akan lambat jika banyak yang menggunakan sehingga perlu dilakukan penelitian ini yang bertujuan untuk mengetahui tingkat kematangan dan menghasilkan rekomendasi guna meningkatkan pengelolaan infrastruktur teknologi informasi. Penelitian dilakukan menggunakan COBIT Framework 4.1 tahap penelitian diawali dengan analisa data wawancara kemudian diidentifikasi IT goals, IT process, serta control objectives. Perhitungan Maturity level untuk mengetahui gap antara kondisi sekarang dengan kondisi yang diharapkan dan rekomendasi digunakan untuk mengatasi gap tersebut. Dari hasil penelitian yang dilakukan diperoleh 4 IT Goals, 10 IT Processes dan 17 detailed control objectives. Karena pemilihan subdomain disesuaikan dengan masalah dan kebutuhan maka subdomain yang digunakan adalah PO3, PO7, Al3 dan Al5. Ditemukan gap sebesar 1.5 dan Maturity level sebesar 2.5 sehingga berada pada level 3 artinya perpustakaan telah memiliki mekanisme dan prosedur yang jelas mengenai tata cara dan manajemen teknologi informasi.
\end{abstract}

Kata Kunci: Tata Kelola, Infrastruktur Teknologi Informasi, COBIT

\begin{abstract}
Based on interviews Library Unit shortage of computer devices and still use servers belonging to Unit Telematics and Wi-Fi access speed will be slow if many are using so we need this study aimed to determine the level of Maturity and produce recommendations to improve the management of information technology infrastructure. The study was conducted using the COBIT 4.1 framework research phase begins with an analysis of the interview data was later identified IT goals, IT processes, as well as the Control Objectives. Calculation Maturity level to determine the gap between the current conditions with the conditions and recommendations are expected to be used to address these gaps. From the results of studies conducted acquired IT Goals 4, 10 IT Processes and 17 detailed control objectives. Because elections subdomain tailored to the issues and needs of the subdomains used is PO3, PO7, Al3 and Al5. Found gap of 1.5 and Maturity level of 2.5 which is in level 3 means the library has had clear mechanisms and procedures concerning the procedures and management of information technology.
\end{abstract}

Keywords: Governance, Information Technology Infrastructure, COBIT

\section{Pendahuluan}

Peranan teknologi informasi dan komunikasi dalam dunia pendidikan sangat besar, khususnya dalam hal penunjang proses belajar-mengajar dan efisiensi pekerjaan akademik maupun administratif. Perguruan tinggi sebagai salah satu institusi pendidikan sudah selayaknya mampu untuk memanfaatkan teknologi informasi dan komunikasi dalam menunjang berbagai aktivitasnya. Implementasi teknologi informasi dan komunikasi pada perguruan tinggi akan memberikan dampak yang sangat positif serta diharapkan memberikan efisiensi dan produktivitas yang tinggi dalam bidang akademik dan administratif [1]. Tata kelola teknologi informasi yang dibutuhkan untuk institusi pendidikan tinggi agar tercipta kenyamanan dan peningkatan pelayanan pada lingkungan Universitas dapat terus ditingkatkan dengan penerapan teknologi

Alit, R. (2017). Tingkat Kematangan Infrastruktur Teknologi Informasi Pada Domain Acquire and Implement Menggunakan COBIT 4.1 (Studi Kasus: UPT Perpustakaan Universitas Pembangunan Nasional "VETERAN" Jawa Timur). KINETIK, 2(3). doi:http://dx.doi.org/10.22219/kinetik.v2i3.32 Makalah dikirim 30 Juni 2017; Revisi 30 Juli 2017; Diterima 1 Agustus 2017 
informasi yang tepat sasaran [2]. Perpustakaan mempunyai peranan yang sangat penting dalam mendukung Tri Dharma perguruan tinggi menjadi pusat sumber informasi dan pengetahuan. Dalam perjalanannya penting untuk memperhatikan apakah penggunaan teknologi informasi yang diterapkan telah sesuai dengan kebutuhan pengguna atau belum, sehingga akan diketahui keberhasilan penerapan sebuah Teknologi Informasi di perpustakaan tersebut. Pengelolaan teknologi informasi di UPT Perpustakaan UPN "Veteran" Jawa Timur juga tidak luput dari dukungan infrastruktur teknologi informasi. Oleh sebab itu, perpustakaan diharapkan mampu mengelola infrastruktur teknologi informasi secara baik agar bisa selaras, salah satunya adalah dengan standarisasi infrastruktur teknologi informasi.

Berdasarkan pengamatan secara langsung dan hasil wawancara didapatkan beberapa kekurangan infrastruktur teknologi informasi, seperti UPT Perpustakaan belum memiliki perangkat hardware berupa server sehingga masih menggunakan server milik UPT Telematika UPN "Veteran" Jawa Timur dan kekurangan perangkat hardware berupa komputer karena banyak yang mengalami kerusakan sehingga mahasiswa dalam menggunakan perangkat tersebut tidak maksimal serta berdasarkan pengamatan secara langsung, jika terlalu banyak mahasiswa yang menggunakan WiFi dalam waktu yang bersamaan maka kecepatan akses WiFi akan lambat. Berdasarkan pengamatan tersebut sehingga perlu dilakukan analisa tata kelola infrastruktur teknologi informasi guna mengetahui apakah penggunaan teknologi informasi saat ini telah sesuai dengan yang diharapkan. Analisa teknologi informasi menggunakan kerangka kerja COBIT bukan hanya memberikan evaluasi terhadap keadaan tata kelola infrastruktur teknologi informasi di UPT Perpustakaan UPN "Veteran" Jawa Timur, akan tetapi dapat juga memberikan masukan yang digunakan untuk memperbaiki pengelolaan infrastruktur teknologi informasi pada perpustakaan ke depannya. Berdasarkan latar belakang yang telah diuraikan di atas, maka didapatkan suatu perumusan permasalahan sebagai berikut: Bagaimana mengetahui tingkat kematangan tata kelola infrastruktur teknologi informasi pada domain Al menggunakan COBIT Framework 4.1. Adapun tujuan dari penelitian ini sebagai berikut untuk mengetahui tingkat kematangan tata kelola infrastruktur teknologi pada domain AI menggunakan COBIT Framework 4.1 .

Dalam penelitiannya [3] bersifat kualitatif dengan menggunakan metode wawancara dan observasi untuk menilai proses-proses dari 4 domain yang terdapat dalam standar Maturity level berbasis COBIT 4.1. Tata kelola teknologi informasi di PT Timah menggunakan 28 proses dan 137 detailed control objectives

Hanya pada 2 domain COBIT 4.1, yaitu PO dan ME terdiri dari 80 detailed control objective sementara domain AI dan DS telah dinilai memenuhi standar pengelolaan teknologi informasi yang baik yaitu pada level 3 (defined) [4]. Tata kelola sistem e-KTP pada Dinas Kependudukan dan Catatan Sipil cukup baik berdasarkan kuesioner yang telah diberikan terhadap domain IT process PO2, PO3, PO6, PO7, Al2, Al3, Al4, Al5, Al7, DS7 dan DS8 [5].

IT governance merupakan salah satu bagian terpenting dari kesuksesan penerapan good corporate governance. IT governance memastikan pengukuran efektivitas dan efisiensi peningkatan proses bisnis perusahaan melalui struktur yang terkait dengan teknologi informasi menuju ke arah tujuan strategis perusahaan. IT governance memadukan best practice proses perencanaan, pengelolaan, penerapan, pelaksaan dan pengawasan kinerja untuk memastikan bahwa teknologi informasi benar mendukung pencapaian perusahaan [6].

Infrastruktur teknologi informasi didefinisikan sebagai sumber daya teknologi bersama yang memberikan layanan dan dukungan. Infrastruktur TI meliputi perangkat keras, perangkat lunak, dan layanan.

COBIT (Control Objectives for Information and Related Technology) merupakan suatu kerangka kerja dan standar tata kelola teknologi informasi yang memberikan kebijakan yang jelas dan praktik yang baik dengan membantu manajemen dalam memahami dan mengelola risiko COBIT dibuat oleh Information Systems Audit and Control Association (ISACA), dan Information Technology Governance Institute (ITGI) pada tahun 1992. Menurut ISACA COBIT berfokus pada apa yang diperlukan untuk mencapai tata kelola yang memadai, pengelolaan IT dan pengendalian IT. Pada umumnya COBIT dipandang sebagai manajemen dan kerangka control IT. COBIT mengelompokkan aktivitas teknologi informasi dalam empat domain, yaitu Plan and Organise (PO), Acquire and Implement (AI), Deliver and Support (DS) serta Monitor and Evaluate (ME). Adapun manfaat dalam penerapan COBIT 4.1 sebagai tata kelola IT COBIT merupakan good practice yang diakui secara Internasional, COBIT terus berkembang, COBIT dapat dipetakan ke kerangka kerja lainnya dan hanya COBIT yang dapat mengelola pengendalian manajemen TI dari awal sampai akhir mengenai siklus TI. 
Proses COBIT digambarkan dengan hubungan antara business objectives, IT governance information, IT resource membagi teknologi informasi menjadi empat domain dan 34 proses sesuai dengan bidang yang bertanggung jawab terhadap perencanaan, membangun, menjalankan dan memonitor implementasi teknologi informasi, dan juga memberikan pandangan teknologi informasi secara keseluruhan dideskripsikan dalam Gambar 1.

\section{BUSINESS OBJECTINES}

\section{GOVERNANCE ORUEGTINES}

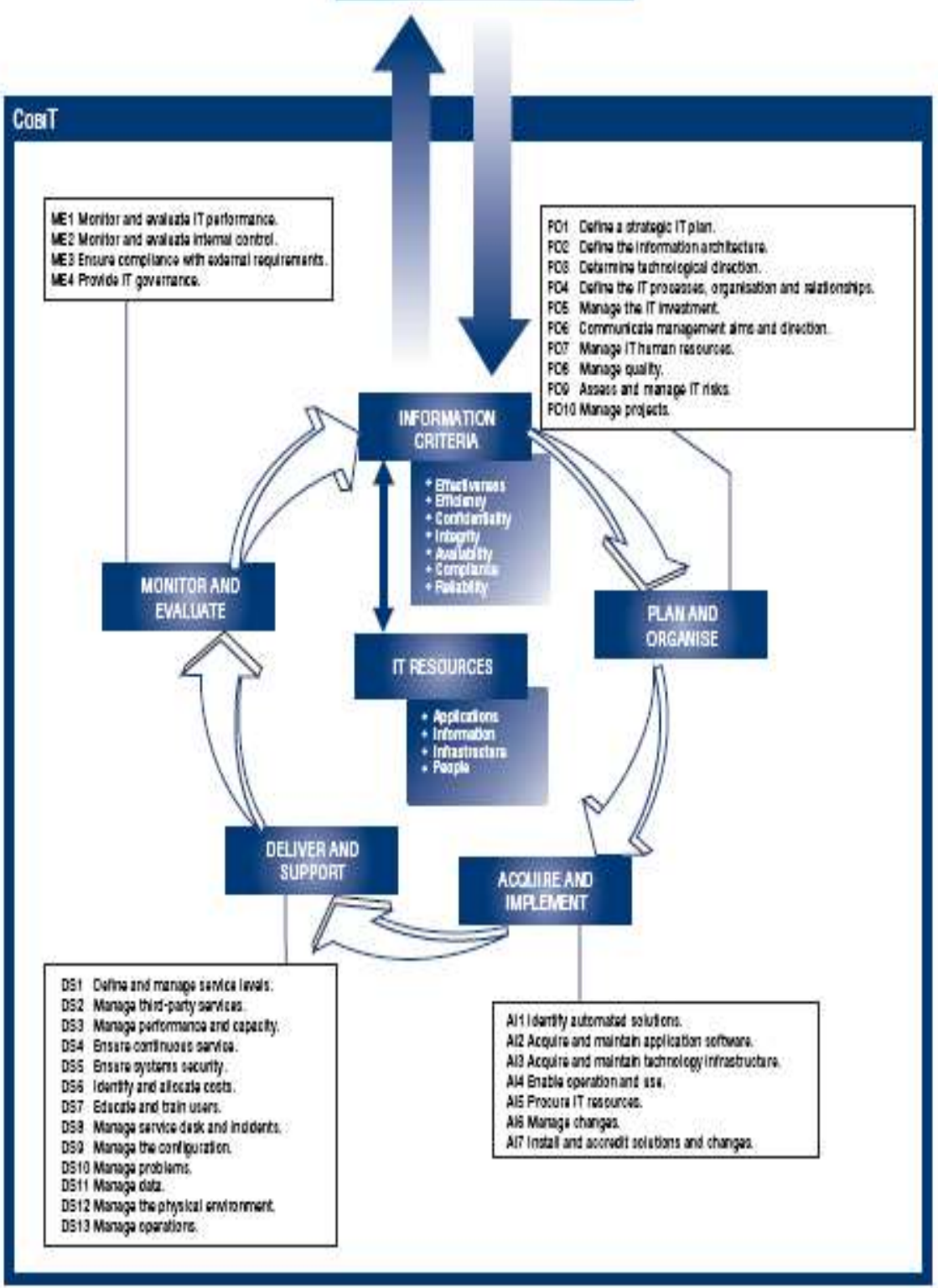

Gambar 1. COBIT Framework [7]

Pengukuran tingkat kematangan diatur pada COBIT untuk tingkat manajemen dan memungkinkan para manajer mengetahui bagaimana pengelolaan dan proses-proses teknologi informasi di organisasi tersebut sehingga bisa diketahui pada tingkatan mana pengelolaannya. Model Kematangan COBIT merupakan alat yang digunakan untuk mengatur seberapa baik proses pengelolaan teknologi informasi yang berhubungan dengan kontrol internal teknologi informasi yang juga berkaitan dengan tujuan bisnis organisasi [8]. 
Pada Gambar 2, COBIT 4.1 tingkat kematangan (Maturity level) manajemen sistem dan teknologi informasi dapat dibagi menjadi enam level [9]. Penentuan tingkat kematangan (Maturity level) didasarkan pada level 0 sampai level 5.

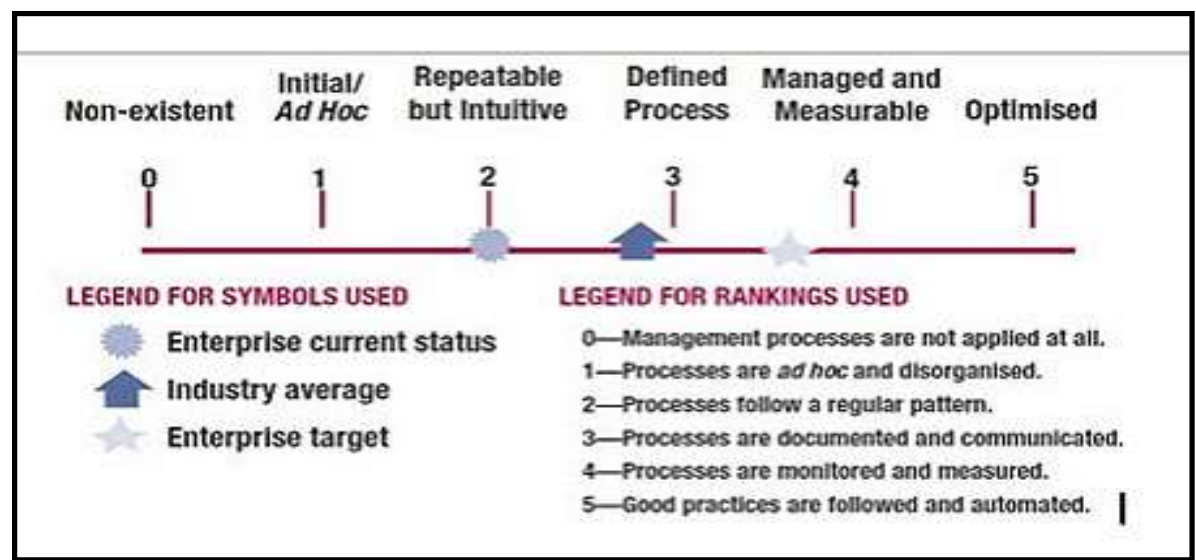

Gambar 2. Maturity Model pada COBIT [7]

\section{Metode Penelitian}

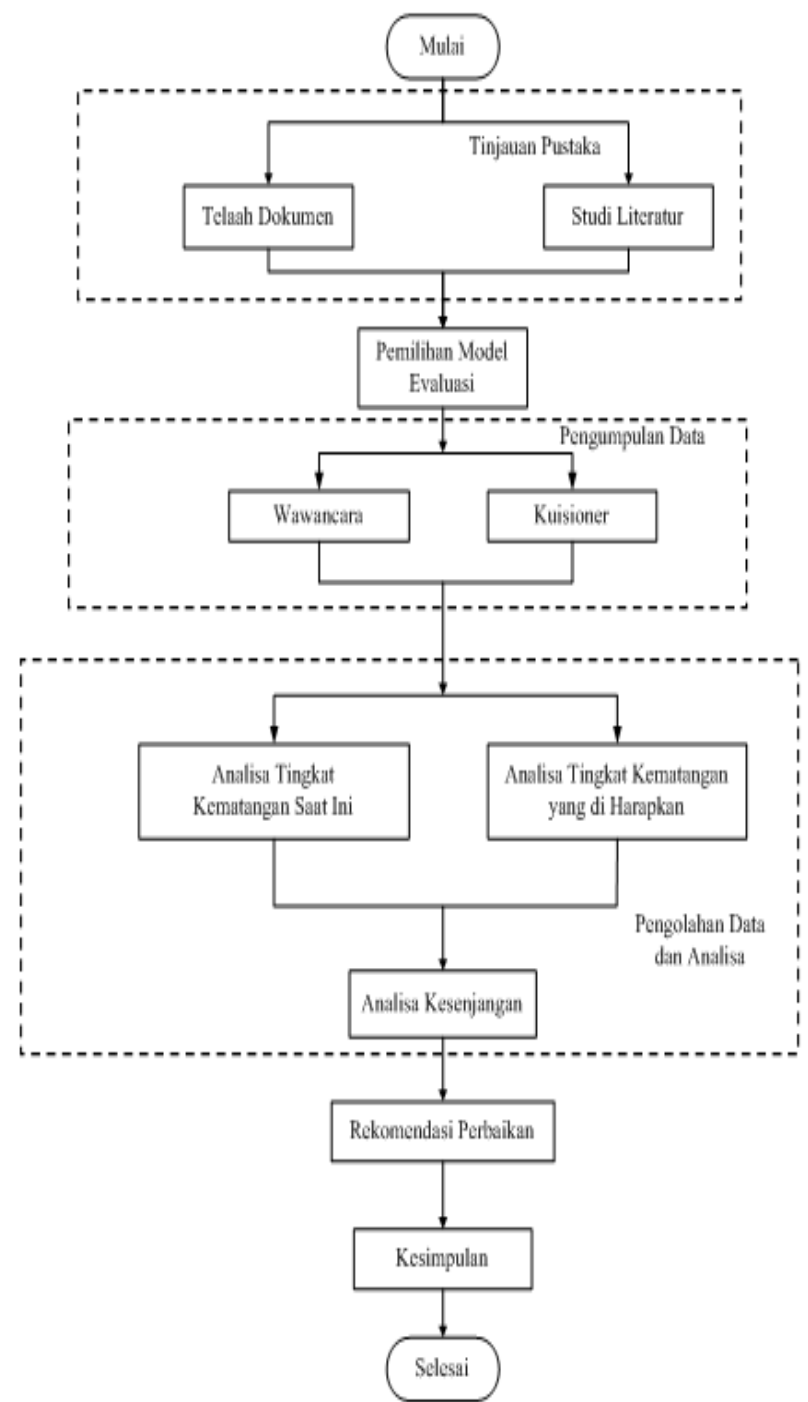

Gambar 3. Alur Penelitian

KINETIK Vol. 2, No. 3, Agustus 2017: 227-234 
Langkah-langkah atau urutan penelitian Gambar 3 bertujuan untuk dapat menemukan kebenaran atau jawaban dari suatu permasalahan adalah:

1. Studi kepustakaan meliputi telaah dokumen dan studi literatur diharapkan mampu menggali informasi yang terkait dengan permasalahan yang akan diteliti dan obyek yang menjadi tujuan penelitian.

2. Pemilihan Model Evaluasi yang akan digunakan adalah model COBIT, karena memiliki cakupan yang sangat luas.

3. Metode penelitian yang digunakan dalam pengumpulan data-data untuk penelitian ini adalah pengamatan secara langsung pada lingkungan (observasi), wawancara dan kuesioner.

4. Analisa data dilakukan untuk mengetahui keadaan tata kelola teknologi informasi saat ini dan akan dijadikan acuan untuk pembuatan rekomendasi. Analisa kesenjangan dilakukan dengan tujuan mengidentifikasi kegiatan yang perlu dilakukan organisasi agar mencapai tingkat keadaan yang diharapkan.

5. Rekomendasi dibuat guna meningkatkan kinerja layanan teknologi informasi.

6. Pada tahap akhir pembuatan saran dan kesimpulan dari penelitian yang dilakukan.

\section{Hasil Penelitian dan Pembahasan}

Data yang didapat dari hasil wawancara diolah sesuai metode COBIT Framework 4.1. Berikut merupakan tahap-tahap pengolahan data.

\subsection{Identifikasi IT Process (Proses TI)}

Tahap ini menetapkan IT process yang sesuai dengan IT goals yang telah disesuaikan dengan studi kasus. Jika disusun menurut domainnya, maka pemetaan IT goals dengan IT process seperti pada Tabel 1.

Tabel 1. IT Process yang Teridentifikasi pada

Perpustakaan UPN "Veteran" Jawa Timur

\begin{tabular}{cc}
\hline IT Domain & IT Process \\
\hline Acquire and Implement $(A I)$ & $\mathrm{Al} 3, \mathrm{Al} 5$ \\
\hline
\end{tabular}

\subsection{Identifikasi Control Objective}

Control objective merupakan bagian dari detail IT process dalam cobit 4.1. Karena disesuaikan dengan studi kasus tidak semua control objective digunakan dalam proses menghitung tingkat kematangan, sehingga diperlukan proses analisa control objective untuk menentukan control objective apa saja yang diperlukan dan akan digunakan dalam proses $\mathrm{TI}$ organisasi. Tabel 2 merupakan detailed control objective yang digunakan dalam penelitian ini.

Tabel 2. Detailed Control Objectives yang Digunakan

\begin{tabular}{|c|c|}
\hline \multicolumn{2}{|r|}{$\mathrm{Al}$ (Acquire and Implement) } \\
\hline$\overline{\mathrm{AI} 3}$ & $\begin{array}{l}\text { Memperoleh dan Memelihara Infrastruktur } \\
\text { Teknologi }\end{array}$ \\
\hline 3.1 & Rencana Pengadaan Teknologi Infrastruktur \\
\hline 3.2 & $\begin{array}{l}\text { Perlindungan Sumber Daya Infrastruktur dan } \\
\text { Ketersediaan }\end{array}$ \\
\hline 3.3 & Pemeliharaan Infrastruktur \\
\hline Al5 & Memenuhi Sumber Daya TI \\
\hline 5.1 & Pengadaan Kontrol \\
\hline 5.2 & Manajemen Kontrak Supplier \\
\hline 5.4 & Pengadaan Sumber Daya TI \\
\hline
\end{tabular}

\subsection{Maturity Level}

Dalam tahap ini dilakukan pengukuran tingkat kematangan yang disesuaikan dengan model kematangan COBIT 4.1. Penentuan tingkat kematangan akan berdasarkan domain yang telah diketahui pada identifikasi control objectives dimana telah ditentukan sebelumnya dari hasil pemetaan IT goals dan IT process. Tingkat kematangan yang didapat menunjukkan ada di level berapakah kematangan penerapan tata kelola infrastruktur teknologi informasi Berikut merupakan rata-rata hasil perhitungan domain Al dijabarkan dalam Tabel 3 dan penjelasan grafik pada Gambar 4. 


\begin{tabular}{clc}
\multicolumn{3}{c}{ Tabel 3. Rata-rata Maturity } \\
\hline Domain & \multicolumn{1}{c}{ Keterangan } & Maturity Level Saat Ini \\
\hline Al3 & $\begin{array}{l}\text { Memperoleh dan } \\
\text { Memelihara } \\
\text { Infrastruktur } \\
\text { Teknologi }\end{array}$ & 2.7 \\
\hline \multirow{2}{*}{ Al5 } & $\begin{array}{l}\text { Memenuhi Sumber } \\
\text { Daya TI }\end{array}$ & 2.3 \\
\hline & Rata-rata & 2.5 \\
\hline
\end{tabular}

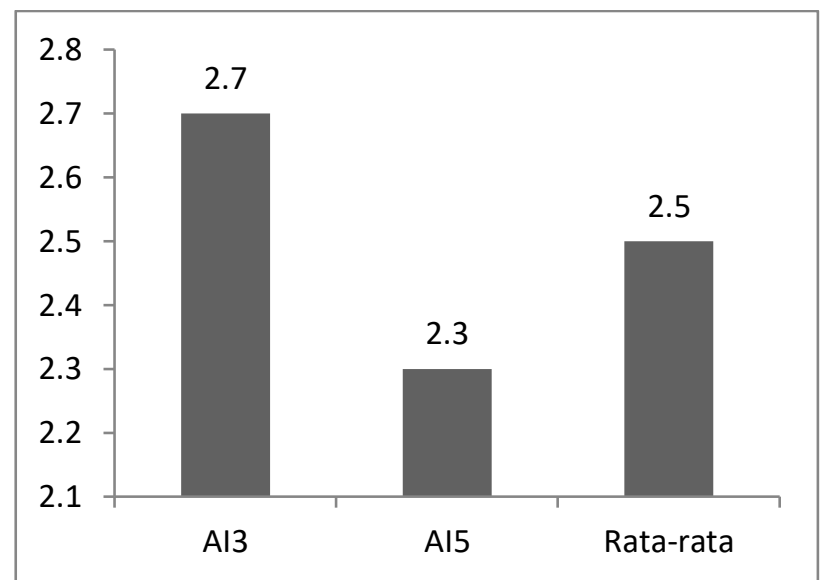

Gambar 4. Grafik Rata-rata Maturity Level Domain Al

Berdasarkan analisa yang dilakukan maka dapat diambil kesimpulan rata-rata perhitungan nilai domain $\mathrm{Al} 3$ dan Al5 dalam tata kelola infrastruktur teknologi informasi berada pada tingkat kematangan sebesar 2.5 dari skala 0-5.

\subsection{Nilai Kesenjangan (Gap)}

Setelah mengetahui kondisi saat ini didapat nilai tingkat kematangan sebesar 2.5 maka dibandingkan dengan kondisi yang diharapkan tingkat kematangan, yaitu sebesar 4 . Tabel 4 serta Gambar 5 menunjukkan nilai kematangan kondisi saat ini dengan nilai kematangan kondisi yang diharapkan.

Tabel 4. Perbandingan Tingkat Kematangan Saat Ini dan Tingkat Kematangan yang Diharapkan

\begin{tabular}{cccc}
\hline \multirow{2}{*}{ Domain } & \multicolumn{3}{c}{ Maturity Level } \\
\cline { 2 - 4 } & Saat Ini & Diharapkan & $\begin{array}{c}\text { Gap (Diharapkan } \\
- \text { Saat Ini) }\end{array}$ \\
\hline Al & 2.5 & 4 & $4-2.5=1.5$ \\
\hline
\end{tabular}

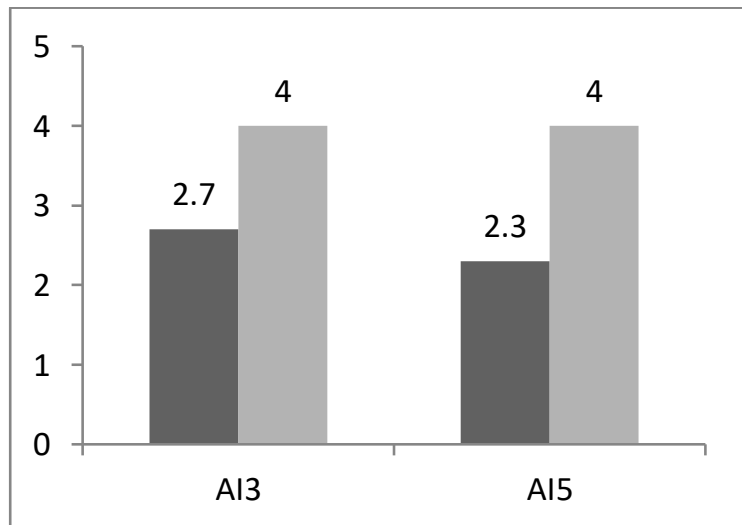

Gambar 5. Grafik Perbandingan Tingkat Kematangan Saat ini dan Tingkat Kematangan Yang Diharapkan Domain Al

KINETIK Vol. 2, No. 3, Agustus 2017: 227-234 
4. Kesimpulan

Kesimpulan yang dapat diambil terkait penelitian ini adalah:

1. Analisa penelitian tata kelola infrastruktur teknologi informasi dengan COBIT 4.1 memiliki ruang lingkup tujuan TI (IT goals) sebanyak 1, proses TI (IT process) sebanyak 2 proses dan dalam perhitungan tingkat kematangan (Maturity level) dilakukan pada 6 detailed control objectives.

2. Berdasarkan hasil perhitungan Maturity level maka diperoleh rata-rata nilai tingkat kematangan pada subdomain Al3 dan Al5 adalah 2.5 dari skala nilai 0 sampai 5 dimana berada pada level 3 (Defined Process) artinya perpustakaan telah memiliki mekanisme dan prosedur yang jelas mengenai tata cara manajemen proses investasi teknologi informasi telah terkomunikasikan serta tersosialisasikan di seluruh jajaran manajemen perusahaan.

\section{Referensi}

[1] F. Rusli, "Rencana Strategis Teknologi Informasi IAIN Raden Fatah Menuju UIN Raden Fatah Palembang," UIN Raden Fatah Palembang, 2015.

[2] F. Adikara, "Implementasi Tata Kelola Teknologi Informasi Perguruan Tinggi Berdasarkan COBIT 5 Pada Laboratorium Rekayasa Perangkat Lunak Universitas Esa Unggul," Universitas Esa Unggul, 2013.

[3] D. R. Kesumawardhani, "Evaluasi IT Governance Berdasarkan COBIT 4.1 (Studi Kasus di PT. Timah (PERSERO) Tbk)," Fakultas Ekonomi Program Ekstensi Akutansi Depok, 2012.

[4] S. W. Sembiring, "Evaluasi Penerapan Teknologi Informasi Menggunakan Model COBIT Framework 4.1 (Studi Kasus: PT.Prudential Indonesia)," Pascasarjana Universitas Atma Jaya Yogyakarta, 2013.

[5] R. S. Pratama, "Analisis Tata Kelola Teknologi Informasi Sistem E-KTP pada Dinas Kependudukan dan Catatan Sipil Kabupaten Ogan Komering Ilir Menggunakan Kerangka Kerja COBIT," Universitas Bina Darma Palembang, 2013.

[6] A. Arumana, A. F. Rochim, and I. P. Windasari, "Analisis Tata Kelola Teknologi Informasi Menggunakan Kerangka Kerja COBIT 4.1 Pada Fakultas Teknik Undip," 2014.

[7] "COBIT 4.1 Framework Control Objectives Management Guidelines Maturity Models," in IT Governance Institute, IT Governance Institute (ITGI), 2007.

[8] M. P. Wibowo, "Analisis Tingkat Kematangan (Maturity Level) Pengawasan dan Evaluasi Kinerja Teknologi Informasi Otomasi Perpustakaan dengan COBIT (Control Objective For Information and Related Technology) Studi Kasus Perpustakaan Universitas Indonesia," Universitas Indonesia, 2008.

[9] R. E. Indrajit, "Integrasi Proses Bisnis Korporat dengan Teknik Pengukuran Kinerja Sistem dan Teknologi Informasi (Implementasi Manajemen Resiko dengan Menggunakan COBIT)," Informatika Bandung, 2005. 
